Schweiz. Z. Tuberk. 1955;12:100-102

\title{
F. Häberlin zum 60. Geburtstag
}

\section{Sehr verehrter, lieber Herr Doktor Häberlin,} Ihre Schüler entbieten Ihnen zum 60. Geburtstag die herzlichsten Glück-wünsche. Wir denken mit Freude und Dankbarkeit an unsere Lehrjahre in Clavadel zurück, während welchen Sie uns durch Ihr Beispiel zeig-ten, wie Sie den Beruf des Arztes auffassen. Ini Mittelpunkt steht für Sie der Patient, dessen Persönlichkeit zu achten oberstes Gesetz ist. So drängten Sie nie einen Patienten zur Operation, sondern batten die Geduld zu warten, bis er sich selbst aus freiem Willen dazu entschließen konnte. Sie kamen als einer der ersten zur Uberzeugung, daß es für die Tuber-kulosepatienten besser ist, dort, wo sie akklimatisiert und Arzten und Schwestern bekannt sind, operiert und weiterbehandelt zu werden und führten daher die Operationen in der Heilstätte selbst durch. Damit haben Sie auch die vollkommene Koordination von Indikationsstellung, Operation und Nachbehandlung erreicht, was in den zwanziger Jahren noch keine Selbstverständlichkeit war. Als Chirurg beherrschten Sie nicht nur die Thoraxchirurgie, sondern waren auch maßgebend beteiligt an der Ent-wicklung der chirurgischen Behandlung der Knochentuberkulose und konnten mit berechtigtem Stolz auf die Erfolge Ihrer Spanimplantationen hinweisen. Durch Ihre sorgfältige Kombination der Klima- und Ruhebehandlung, der internistischen mit der chirurgischen Therapie erzielten Sie die besten Resultate und erwarben sich damit das Vertrauen Ihrer Patienten. Dank Ihrer ehrlichen und herzlichen Anteilnahme am Geschick Ihrer Kranken sind Sie der «verehrte Arzt» ungezählter Patienten geworden. Ihre liberale Weltanschauung, die Sie aus dem Elternhaus und Ihrer Landpraxis in Amerika mitbrachten, bewahrte Sie davor, doktrinär zu werden. Sie ließen die Meinung anderer gelten und legten den größten Wert darauf, jedem einzelnen Fall gerecht zu werden. Wir haben bei Ihnen gelernt, ärztliche Pflichterfüllung mit Freude am Beruf zu verbinden, und so sind aus Ihrer Schule nicht nur Tuberkulosespezialisten, sondern auch viele praktische Ärzte hervorgegangen, die, zerstreut in der ganzen Schweiz und im Ausland, Ihre Auffassungen weitertragen.

Wir danken Ihnen für alles, was Sie uns gegeben haben. Im Namen Ihrer Schüler: Dänzer, Davos Steinlin, Heiligenschwendi 